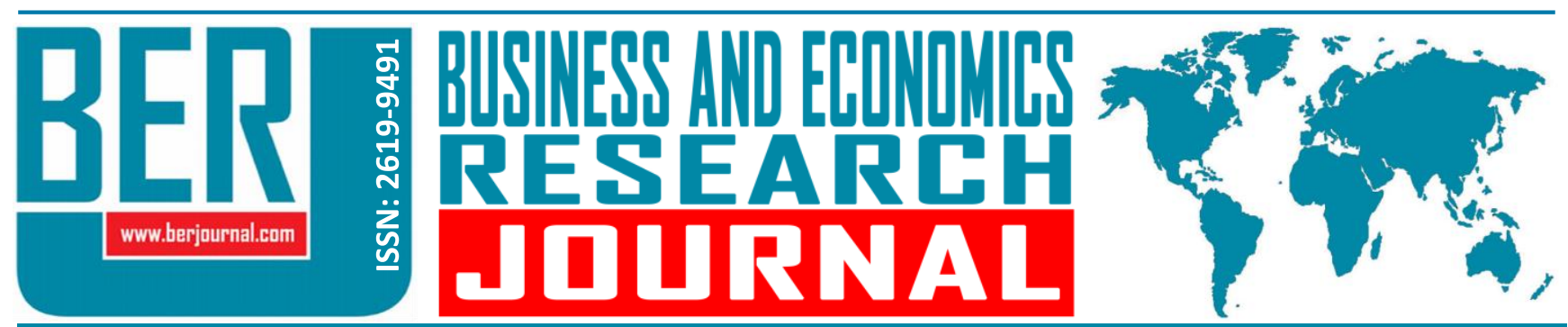

Business and Economics Research Journal Vol. 10, No. 5, 2019, pp. 1085-1093 doi: 10.20409/berj.2019.223

\section{Türkiye'de Reel Konut Fiyatlarında Balonların Varlığı Üzerine Uygulamalı Bir Analiz}

\author{
Omer Iskenderoglu ${ }^{\mathrm{a}}$, Saffet Akdag
}

Öz: Spekülatif hareketler nedeniyle varlık fiyatlarındaki artış olarak ifade edilen fiyat balonlarının tespiti gelecek dönemlerde ortaya çıkabilecek potansiyel finansal dengesizlikler konusunda bilgi sağlayabilmektedir. Özellikle son uluslararası finansal kriz olan ve bütün dünyayı etkisi altına alan Mortgage krizinin, konut fiyatlarında meydana gelen fiyat balonlardan kaynaklandığı düşünüldügünde, ulusal ölçekte konut fiyatlarında balon oluşup oluşmadığının tespiti ekonomik açıdan önem arz etmektedir. Bu çalışmada da Türkiye'de konut fiyatlarında balon oluşup oluşmadığının tespit edilmesi amaçlanmıştır. Bu bağlamda Ocak 2010 ile Aralık 2018 tarihleri arasında ve Türkiye geneli ile Ankara, İstanbul ve izmir şehirleri için aylık reel hedonik konut fiyat endeksi kullanılarak, konut fiyatlarında balon oluşup oluşmadığı Sup-Augmented Dickey Fuller ve Generalized Sup-Augmented Dickey Fuller testleriyle incelenmiştir. Her iki test sonucuna göre Türkiye geneli ile istanbul ve izmir şehirlerinde konut fiyatlarında balonların var olduğu tespit edilmiştir. Ankara şehrinde ise Sup-Augmented Dickey Fuller test sonucuna göre konut fiyatlarında balonunun oluştuğu ancak Generalized Sup-Augmented Dickey Fuller test sonucuna göre ise konut fiyatlarında balonunun oluşmadığı tespit edilmiştir.

\section{An Applied Analysis on the Presence of Price Bubbles of Real Estate Prices in Turkey}

\begin{abstract}
The detection of price bubbles, which are expressed as increases in asset prices due to speculative movements, can provide information regarding potential financial imbalances that may arise in the future. Upon considering that the Mortgage crisis, which is the last international financial crisis and affected the whole world, was caused by the price bubbles in the housing prices, it is of economic importance to determine whether or not such bubbles occur in the housing prices on the national scale. This study aims to determine whether or not price bubbles occur in housing prices in Turkey. In this context, it is tried to be examined whether or not price bubbles occurred in Turkey via the Sup-Augmented DickeyFuller and the Generalized Sup-Augmented Dickey-Fuller tests utilizing the monthly data of the real hedonic housing price index obtained from the cities of Ankara, Istanbul, and Izmir over the period from January 2010 to December 2018. According to the study results in both test results, the existence of housing price bubbles in the cities of Istanbul and Izmir is detected. The Sup-Augmented Dickey-Fuller test results indicate that housing price bubbles occur in Ankara, whereas no housing price bubbles are detected in the city according to results obtained from the Generalized Sup-Augmented Dickey-Fuller test.
\end{abstract}

Anahtar Sözcükler: Fiyat Balonu, Hedonik Konut Fiyat Endeksi, SADF, GSADF, Türkiye

JEL: C22,G12, G17, R31

$\begin{array}{ll}\begin{array}{l}\text { Geliş } \\ \text { Düzeltme }\end{array} & : \text { 13 Mayıs } 2019 \\ \text { Kabul } & : \text { 16 Aemmuz } 2019 \\ & \text { Türstos } 2019 \\ \text { Tür } & : \text { Araştırma }\end{array}$

Keywords: Price Bubble, Hedonic Real Estate Price Index, SADF, GSADF, Turkey

JEL: C22, G12, G17, R31

a Prof., PhD., Nigde Omer Halisdemir University, Faculty of Economics and Administrative Sciences, Department of Business, Nigde, Turkiye, oiskenderoglu@ohu.edu.tr (ORCID ID: 0000-0002-3407-1259)

b Asst. Prof., PhD., Tarsus University, Faculty of Applied Sciences, Department of Banking and Finance, Mersin, Turkiye, ekonomisyen@yahoo.com (ORCID ID: 0000-0001-9576-6786) 


\section{Giriş}

Finansal piyasalarda varlıkların fiyatlarının gerçek değeri yansıtıp yansıtmadığı finans biliminin farklı alanlarındaki çeşitli teori ve hipotezlerin oluşmasına neden olmaktadır. Arbitraj olanaklarının varlığı varsayımına sahip bütün finans teorileri kendi içerisinde varlıkların piyasada gerçek değerlerini yansıttıklarını kabul eder. Ancak çeşitli içsel ve dışsal sebeplerle oluşan piyasa dengesinden sapma, etkin piyasalar hipotezi ve indirgenmiş nakit akışları yaklaşımı gibi birçok tartışmanın ortaya çıkmasına yol açmaktadır (Fama, 1991; Campbell ve Shiller, 1987). Birçok ampirik çalışmada piyasalardaki spekülatif hareketlerin varlık fiyatlarında balonlara neden olduğu ifade edilmiştir (Santoni 1987; Diba ve Grosman, 1998; Shiller, 2003; Brunnermeier, 2008; Lind, 2009). Fiyat balonu en basit tanımla, bir varlığın piyasa fiyatının temel değerinden sapmasıdır (Hu ve Oxley, 2017: 420). Bir varlığın gerçek fiyatının ilk olarak birkaç ay veya yıl boyunca çarpıcı bir şekilde artması ve ardından neredeyse hemen hemen dramatik bir şekilde düşmesi durumunda bir balonun varlığından bahsedilir (Lind, 2009: 80). Piyasalarda fiyat balonlarının oluşması ise birçok farklı birim açısından önemsenmesi gereken bir durumdur. Finansal tarihçilerin de iddia ettiği üzere finansal krizlerin büyük çoğunluğu genellikle finansal varlıkların fiyatlarında oluşan balonlardan kaynaklanmaktadır (Ahamed, 2009). Spekülatif hareketlerden kaynaklı olarak fiyat balonlarının oluştuğu dönemlerde yatırımcılar rasyonel olmayan yatırımlara yönelmektedir. Çünkü bu dönemde yükselen fiyatlar, yatııımcıları daha fazla fiyat artışı beklentisine sokmaktadır. Bu beklentilerin sonucunda oluşan aşırı talep varlık fiyatlarının daha da artmasına neden olmaktadır. Bu ise olası bir finansal krizin daha şiddetli yaşanmasına neden olabilmektedir. Tüm temel ekonomi kitaplarında açıklanan 1929 bunalımında dahi hisse senetlerinin fiyat ve getirilerindeki aşırı artıştan söz edilmektedir. Özellikle varlık fiyatlarından balon oluştuğu dönemde, varlıklar yatırımcılar için gittikçe daha çekici hâle gelmekte böylelikle artan talep nedeniyle varlıkların fiyatlarında daha da fazla artış yaşanmaktadır. Bir noktadan sonra insanlar fiyatların daha fazla artmayacağını düşünmekte, böylelikle balonlar sona ermekte, talep düşmekte ve piyasalar hareketsiz hâle gelmektedir (Case ve Shiller, 2003: 299301; Shiller, 2003: 97). Detayları başka çalışmaların konusunu oluşturmak üzere 2008 küresel ekonomik krizinin büyük ölçüde konut piyasalarında meydana gelen balonlardan kaynaklandığı söylenebilir. Özellikle $A B D$ 'deki yüksek faizli ipotek ve birçok Avrupa ülkesinde konut yatııımının aşırı artması konut fiyatlarında balonların oluşmasına neden olmuş ve sonrasında da yayılım etkisiyle küresel bir krizin meydana gelmesine yol açmıştır (Shi, Valadkhani, Smyth ve Vahid, 2016: 591).

Varlıkların fiyatlarında meydana gelen balonları tespit etmek amacıyla birçok yöntem kullanılmaktadır. Fiyat balonu tespit yöntemleri arasında, Shiller (1981) ve LeRoy ve Porter (1981) çalışmalarında önerilen varyans testleri ilk sıralardadır. Bunun dışında fiyat balonunu tespit etmek amacıyla önerilen bir diğer yöntem ise Diba ve Grossman (1984) ve Hamilton ve Whiteman (1985) çalışmalarında ifade edilen ve yaygın olarak kullanılan durağanlık testleridir. Ayrıca, Campbell ve Shiller (1987) çalışmasında birim kök ve eşbütünleşme testleri önerilmektedir (Fabozzi, Kynigakis, Panopoulou ve Tunaru, 2019: 2). Homm ve Breitung'un (2012) çalışmasında ise fiyat balonlarını ölçmeye yönelik Chow ve CUSUM testleri önerilmektedir. Ayrıca Phillips, Wu ve Yu'nun (2011) çalışmasında tanıtılan ve Phillips Shi ve Yu'nun (2015a) çalışmasında geliştirilen, SADF (Sup-Augmented Dickey-Fuller) ve GSADF (Generalized Sup-Augmented Dickey-Fuller) testleri de literatürde yer alan fiyat balonlarının tespitinde kullanılan diğer yaygın testlerdir.

Bu çalışmada Türkiye geneli ile Ankara, İstanbul ve İzmir şehirleri için konut fiyatlarında balon oluşup oluşmadığının tespit edilmesi amaçlanmıştır. Literatürde yer alan diğer çalışmalarda genellikle konut fiyat endeksi kullanılırken, bu çalışmada benzer çalışmalardan farklı olarak enflasyondan arındırılmış hedonik konut fiyat endeksi kullanılmıştır. Hedonik fiyat endeksi kullanılarak, konutların kalitesi nedeniyle ortaya çıkabilecek fiyat artışlarının önüne geçilmektedir. Ayrıca ilgili endeks enflasyondan da arındırılarak reel fiyatlardaki değişim ortaya konmaktadır. Çalışma sonucunda hedonik reel konut fiyatlarında balonların varlığını gösteren bulguların olması yönüyle çalışmanın literatüre özgün bir katkı sağlayacağı düşünülmektedir. Çalışma beş bölümden oluşmakta olup birinci bölümde fiyat balonları ve fiyat balonlarının tespitinde kullanılan yöntemler hakkında temel bilgiler verilirken, ikinci bölümde konut fiyatlarında balonların varlığına yönelik yapılan ulusal ve uluslararası çalışmalardan oluşan literatür yer almaktadır. Üçüncü bölümde veri ve metodoloji hakkında bilgi verilmiş, dördüncü bölümde ise analiz sonucunda ulaşılan bulgulara yer verilmiştir. Çalışmanın son bölümü ise genel bir değerlendirmeden oluşmaktadır. 


\section{Literatür}

Konut fiyatlarında balonların varlığına yönelik literatürde yer alan çalışmalar Tablo 1'de özetlenmiştir. Literatürde yer alan çalışmalar değerlendirildiğinde, farklı sonuçlara ulaşılan çalışmalar olmakla birlikte, çalışmaların çoğu konut fiyatlarında zaman zaman fiyat balonlarının meydana geldiğini göstermektedir. Özellikle ABD özelinde yapılan çalışmalarda ülkede konut fiyatlarında balonların varlığına dair anlamlı sonuçlara ulaşılmıştır.

Tablo 1. Literatür Özeti

\begin{tabular}{|c|c|c|c|c|}
\hline Çalışma & Yöntem & Ülke & Veri & Sonuç \\
\hline $\begin{array}{l}\text { Case ve Shiller } \\
(2003)\end{array}$ & Anket Yöntemi & $\begin{array}{l}\text { ABD'de } 41 \\
\text { Eyalet }\end{array}$ & $\begin{array}{l}\text { Ocak } 1985 \text { - Mart } 2002 \\
\text { tarihleri arasındaki } \\
\text { konut fiyatları }\end{array}$ & $\begin{array}{l}\text { Genel olarak konut } \\
\text { fiyatlarında balonların } \\
\text { var olduğuna dair güçlü } \\
\text { kanıtlar bulunduğu ifade } \\
\text { edilmiştir. }\end{array}$ \\
\hline $\begin{array}{l}\text { Chen ve Funke } \\
\text { (2012) }\end{array}$ & SADF testi & Almanya & $\begin{array}{l}\text { 1987:3 - 2012:4 } \\
\text { tarihleri arasında } \\
\text { çeyrek dönemlik konut } \\
\text { fiyatları endeksi }\end{array}$ & $\begin{array}{l}\text { Almanya'da konut } \\
\text { fiyatlarında balonların } \\
\text { var olmadığı sonucuna } \\
\text { ulaşılmıştır. }\end{array}$ \\
\hline $\begin{array}{l}\text { Engsted, Hviid } \\
\text { ve Pedersen } \\
(2015)\end{array}$ & GSADF testi & 18 OECD Ülkesi & $\begin{array}{l}1970-2013 \text { yılına kadar } \\
\text { konut fiyatları } \\
\text { endeksinin çeyreklik } \\
\text { verileri }\end{array}$ & $\begin{array}{l}\text { Almanya ve İtalya hariç } \\
\text { diğer ülkeler için konut } \\
\text { fiyatlarında balonların } \\
\text { oluştuğu tespit } \\
\text { edilmiştir. }\end{array}$ \\
\hline $\begin{array}{l}\text { Zeren ve } \\
\text { Ergüzel (2015) }\end{array}$ & SADF ve GSADF testi & $\begin{array}{l}\text { İstanbul, } \\
\text { Ankara ve İzmir }\end{array}$ & $\begin{array}{l}\text { Ocak } 2010 \text { - Haziran } \\
2014 \text { tarihleri arasında } \\
\text { konut fiyat endeksinin } \\
\text { aylık verileri }\end{array}$ & $\begin{array}{l}\text { İlgili şehirlerde konut } \\
\text { fiyatlarında balonların } \\
\text { var olmadığı ifade } \\
\text { edilmiştir. }\end{array}$ \\
\hline $\begin{array}{l}\text { Escobari ve } \\
\text { Jafarinejad } \\
(2016)\end{array}$ & GSADF testi & $A B D$ & $\begin{array}{l}\text { Ocak } 1980 \text { - Eylül } 2013 \\
\text { arasında aylık } \\
\text { gayrimenkul yatırım } \\
\text { ortaklığı endeksi verileri }\end{array}$ & $\begin{array}{l}\text { İlgili endekste balonların } \\
\text { var olduğu sonucuna } \\
\text { ulaşılmıştır. }\end{array}$ \\
\hline $\begin{array}{l}\text { Shi, } \\
\text { Valadkhani, } \\
\text { Smyth ve } \\
\text { Vahid (2016) }\end{array}$ & GSADF testi & Avustralya & $\begin{array}{l}\text { Aralık } 1995 \text { - Ocak } 2016 \\
\text { arasında aylık konut } \\
\text { fiyatları endeksi verileri }\end{array}$ & $\begin{array}{l}\text { Çalışma sonuçları konut } \\
\text { fiyatlarında balonların } \\
\text { oluştuğunu ortaya } \\
\text { koymaktadır. }\end{array}$ \\
\hline $\begin{array}{l}\text { Coşkun ve } \\
\text { Jadevicius } \\
(2017)\end{array}$ & SADF ve GSADF testi & $\begin{array}{l}\text { Ankara, } \\
\text { İstanbul ve } \\
\text { İzmir }\end{array}$ & $\begin{array}{l}\text { Ocak } 2010 \text { - Aralık } 2014 \\
\text { tarihleri arasında aylık } \\
\text { konut fiyat endeksleri }\end{array}$ & $\begin{array}{l}\text { Türkiye'de konut } \\
\text { fiyatlarında balonların } \\
\text { var olmadığı sonucuna } \\
\text { ulaşılmıştır. }\end{array}$ \\
\hline $\begin{array}{l}\text { Coşkun, Seven, } \\
\text { Ertugrul ve Alp } \\
\text { (2017) }\end{array}$ & $\begin{array}{l}\text { OLS/FMOLS/DOLS, } \\
\text { Kalman filteri ve ARIMA } \\
\text { modelleri }\end{array}$ & Türkiye & $\begin{array}{l}\text { Ocak 2010- Aralık } 2014 \\
\text { ve Haziran 2007- } \\
\text { Aralık } 2014 \text { tarihleri } \\
\text { arasında konut fiyat } \\
\text { endeksi }\end{array}$ & $\begin{array}{l}\text { Konut fiyatlarında bazı } \\
\text { aşırı değerleme } \\
\text { durumlarının var olduğu } \\
\text { ancak balon oluşmadığı } \\
\text { ifade edilmiştir. }\end{array}$ \\
\hline $\begin{array}{l}\text { Afşar ve Doğan } \\
\text { (2018) }\end{array}$ & SADF ve GSADF testi & Türkiye & $\begin{array}{l}\text { Ocak } 2010 \text {-Kasım } 2017 \\
\text { tarihleri arasında aylık } \\
\text { konut fiyat endeksi }\end{array}$ & $\begin{array}{l}\text { Türkiye'de konut } \\
\text { fiyatlarında balon } \\
\text { oluşmadığı sonucuna } \\
\text { ulaşılmıştır. }\end{array}$ \\
\hline Çağlı (2018) & $\begin{array}{l}\text { Chen ve diğ. (2017) } \\
\text { tarafında geliştirilen" co- } \\
\text { moving systems" modeli }\end{array}$ & $\begin{array}{l}\text { Türkiye ve } \\
\text { konut fiyat } \\
\text { endeksi } \\
\text { hesaplanan iller }\end{array}$ & $\begin{array}{l}\text { Ocak } 2010 \text { ile Aralık } \\
2017 \text { tarihler arasında } \\
\text { konut fiyat endeksleri } \\
\text { hesaplanan tüm } \\
\text { şehirlerin aylık verileri }\end{array}$ & $\begin{array}{l}\text { Ülke genelinde konut } \\
\text { fiyatlarında balonların } \\
\text { var olduğu ifade } \\
\text { edilmiştir. }\end{array}$ \\
\hline
\end{tabular}


Tablo 1. Literatür Özeti (Devamı)

\begin{tabular}{|l|l|l|l|l|}
\hline Çalışma & Yöntem & Ülke & Veri & Sonuç \\
\hline $\begin{array}{l}\text { Evrim } \\
\text { Mandacı ve } \\
\text { Çağı (2018) }\end{array}$ & GSADF testi & $\begin{array}{l}\text { Türkiye geneli ve } \\
\text { konut fiyat endeksi } \\
\text { hesaplanan iller }\end{array}$ & $\begin{array}{l}\text { Ocak 2010 ile Nisan 2017 } \\
\text { tarihleri arasında konut fiyat } \\
\text { endeksleri hesaplanan tüm } \\
\text { şehirlerin aylık verileri }\end{array}$ & $\begin{array}{l}\text { Türkiye genelinde, } \\
\text { spekülatif balonların varlığına } \\
\text { ilişkin güçlü kantlar elde } \\
\text { edildiği ve balonların } \\
\text { genellikle Anadolu'nun } \\
\text { batı ve kıyı şeridi bölgelerinde } \\
\text { oluştuğu ifade edilmiştir. }\end{array}$ \\
\hline $\begin{array}{l}\text { Fabozzi ve } \\
\text { Xiao (2018) }\end{array}$ & $\begin{array}{l}\text { Dickey- } \\
\text { Fuller t } \\
\text { istatistiği }\end{array}$ & ABD & $\begin{array}{l}\text { Ocak 1991 - Şubat 2015 } \\
\text { tarihleri arasında ev fiyatları } \\
\text { endeksinin aylık verileri }\end{array}$ & $\begin{array}{l}\text { Mortgage krizinden önce } \\
\text { konut fiyatlarında balonların } \\
\text { olduğu sonucuna ulaşılmıştır. }\end{array}$ \\
\hline $\begin{array}{l}\text { Hu ve Oxley } \\
\text { (2018) }\end{array}$ & GSADF testi & Japonya & $\begin{array}{l}\text { 1970 ilk çeyreği ile 1999 son } \\
\text { çeyreği arasında çeyreklik } \\
\text { konut endeksi verileri }\end{array}$ & $\begin{array}{l}\text { Japonya'da konut fiyatlarında } \\
\text { balonun var olduğu ifade } \\
\text { edilmiştir. }\end{array}$ \\
\hline
\end{tabular}

Tablo 1'de yer alan çalışmalardan Türkiye özelinde gerçekleştirilen çalışmalar değerlendirildiğinde Çağı̆ (2018) ve Evrim Mandacı ve Çağlı'nın (2018) çalışması haricindeki çalışmalarda Türkiye'de konut fiyatlarında balonların var olmadığı ifade edilmiştir. Chen vd. (2017) tarafından geliştirilen "co-moving systems" modelinin ve hedonik fiyat endeksinin kullanıldığı Çağı (2018) çalışmasında ve GSADF ve hedonik fiyat endeksinin kullanıldığı Evrim Mandacı ve Çağlı'nın (2018) çalışmasında Türkiye geneli ile konut fiyat endeksi hesaplanan tüm iller ve il grupları üzerinde gerçekleştirilen analiz sonucunda Türkiye'deki konut fiyatlarında balonların var olduğu ifade edilmiştir. Bu çalışmada benzer çalışmalardan farklı olarak hedonik fiyat endeksi enflasyondan arındırılarak analizde kullanılmıştır. Hedonik konut fiyat endeksinin kullanılması analizin sağlıklı sonuç vermesi açısından önem arz etmektedir. Çünkü her varlıkta olduğu gibi konutlarda da tüketici tercihlerinden ve konut sektöründeki inovasyon uygulamalarından kaynaklanan kalite değişimleri görülebilmektedir. Ayrıca konut piyasasının heterojen olması nedeniyle, konutlardaki kalite değişimlerinin fiyatlara etkisini belirlemek zor olmaktadır. Bu nedenle, konut fiyatlarında meydana gelen değişimler saf fiyat değişimlerini gösterebildiği gibi konutların kalitesindeki değişimleri de gösterebilmektedir. Bu bağlamda konut fiyatlarında meydana gelen bir artışın, kalite artışı nedeniyle ortaya çıkması durumunda bu artışları balon olarak değerlendirmek yanıltıcı olabilir (Hülagu Kızılkaya, Özbekler ve Tunar 2016: 2). Bu nedenle hedonik konut fiyat endeksinin kullanılması analiz sonuçlarının doğruluğu açısından önem arz etmektedir. Hedonik konut fiyat endeksi başta ABD olmak üzere birçok ülke tarafından konutların kalite etkisinden arındırılmış fiyatlarındaki değişimleri izlemek amacıyla hesaplanmaktadır.

\section{Veri ve Metodoloji}

Bu çalışmada Türkiye Cumhuriyeti Merkez Bankası (TCMB) tarafından aylık olarak yayınlanan Türkiye geneli ile Ankara, İstanbul ve İzmir şehirleri için hedonik konut fiyat endeksi kullanılarak bir dizi analiz gerçekleştirilmiştir. Merkez Bankası hedonik konut fiyat endeksini Türkiye geneli, Ankara İstanbul ve İzmir illeri ve diğer illeri de gruplayarak 23 il grubu için ayrı ayrı aylık olarak hesaplayıp yayınlamaktadır. "Hedonik konut fiyat endeksi Türkiye'deki konutların gözlemlenebilen özelliklerinin zaman içinde kontrol edilerek, kalite etkisinden arındırımış fiyat değişimlerini izlemek amacıyla hesaplanmaktadır" (TCMB). Analizde kullanılan hedonik konut fiyat endeksi verileri enflasyon etkileri içerebileceğinden aylık TÜFE oranı ile aşağıdaki yöntem (1) kullanılarak Kim ve Lee (2000), Atasever (2016), Glaeser vd. (2017) çalışmalarına benzer şekilde konut fiyat endeksleri enflasyondan arındırılmıştır.

$$
\text { Reel Hedonik Konut Fiyat Endeksi }=\frac{\text { Nominal Hedonoik Konut Fiyat Endeksi }}{1+\text { Aylık Tüfe Oranı }}
$$


Hesaplanan reel hedonik konut fiyat endeksi kullanılarak gerçekleştirilen analiz, Ocak 2010 ile Aralık 2018 tarihleri arasında 108 gözlem üzerinden gerçekleştirilmiştir. Analizde Phillips vd.'nin (2011) çalışmasında geliştirilen SADF ile Phillips vd.'nin (2015a) çalışmasında geliştirilen GSADF testleri kullanılmıştır. Konuyla ilgili olarak Diba ve Grossman'ın (1988) çalışmasında, borsadaki potansiyel rasyonel kabarcıkların belirlenmesi amacıyla, sağa kuyruklu birim kök testlerinin kullanılması önerilmiştir. Nitekim Gürkaynak'ın (2008) çalışmasında da belirtildiği gibi, standart birim kök ve eşbütünleşme testlerinin "ex-post", GSADF testinin ise tahminleme prosedürü itibariyle "ex-ante" olduğu ve bu bağlamda standart birim kök testlerinin fiyat balonlarını tespit etmede yetersiz kalabileceği ifade edilmiştir. Phillips vd.'nin (2011) çalışmasında ise spekülatif fiyat artışına dair başlangıç ve bitiş tarihlerini de içeren kanıtları test edebilecek, SADF temelli bir test önerilmiştir. Ayrıca Homm ve Breitung (2012), SADF testinin fiyat kabarcıklarını tespit etmek amacıyla kullanılabileceğini ortaya koyan etkili bir simülasyon çalışması gerçekleştirmiştir. Ancak Phillips vd.'nin (2015a) çalışmasında SADF testinin çoklu baloncukların varlığını tespit etme konusunda sınırı bir yeteneğe sahip olduğu ifade edilmiş ve çoklu baloncukların tespitinde daha başarılı olan GSADF testi önerilmiştir. Bu durumda yönteme ilişkin literatürün ışığında, hem SADF hem de GSADF testleri ile konunun incelenmesi daha geniş bir bakış açısı sağlayabileceğinden her iki yöntem de analizlerde kullanılmıştır. Analiz Eviews programında RTADF eklentisi kullanılan ve Caspi (2013) çalışmasında önerilen prosedür izlenerek gerçekleştirilmiştir.

SADF ve GSADF test istatistiğinde birim kök hesaplamaları yapılırken aşağıdaki regresyon modeli (2) kullanılır (El Montasser, Gupta, Martins ve Wanke 2015: 21):

$$
y_{t}=m+\lambda y_{t-1}+\sum_{i=1}^{p} \alpha_{i} \Delta y_{t-i}+\epsilon_{t}, \epsilon_{t} \text { iid } N\left(0, \sigma^{2}\right), t=1, \ldots, T
$$

Standart ADF testi ise $y_{t-1}$ katsayısının $(\lambda)$ ilgili katsayısının standart hatasına (se $\left.\lambda\right)^{\prime}$ ye bölünmesi şeklinde oluşturulan aşağıdaki denklem (3) ile hesaplanmaktadır.

$$
A D F_{r 1, r 2}=\frac{\lambda_{r 1, r 2}}{\operatorname{se}\left(\lambda_{r 1, r 2}\right)}
$$

GSADF testinin hesaplanabilmesi için denklem 2'de tanımlanan regresyon denklemi ile birden çok alt örneklem için tekrarlanan sağ kuyruklu ADF testlerine ulaşılacaktır. Alt örneklemlerin hem bitiş noktası $\left(r_{2}\right)$ hem de başlangıç noktası $\left(r_{1}\right)$ dinamik bir şekilde değişmekte sıfır noktasından farklılaşması sonucu alt örneklemler ortaya çıkmaktadır. Örneklem aralığının 0 ile 1 arasında olduğu değerlendirildiğinde alt örneklemlerin başlangıç noktasının 0 ile $r_{2}-r_{0}$ aralı̆̆ında; bitiş noktasının ise $r_{0}$ ile 1 aralığında değişen değerler alması beklenmektedir. Burada $r_{0}$ minimum tahmin penceresi uzunluğunu ifade etmektedir. (Evrim Mandacı ve Çağlı, 2018: 96-97).

SADF ve GSADF test hesaplamaları ise aşağıdaki gibi ifade edilebilir (Phillips vd., 2015a:1048-1049):

$$
\begin{aligned}
& \operatorname{SADF}_{r_{2}}\left(r_{0}\right)=\sup _{r_{1} \in\left[0, r_{2}-r_{0}\right]} A D F_{r_{1}}^{r_{2}} \\
& \operatorname{GSADF}\left(r_{0}\right)=\sup _{r_{2} \in\left[r_{0}, 1\right]} S A D F_{r_{2}}(r 0)
\end{aligned}
$$

SADF ve GSADF birim kök testlerinde fiyat balonunun var olduğunu ifade eden boş hipotez $\mathrm{H}_{0}$ : $\lambda=1^{\prime} \mathrm{e}$ karşılık birim kök testlerinde fiyat balonunun var olmadığını ifade eden alternatif hipotez $\mathrm{H}_{1}: \lambda>1$ test edilir. Tekrarlamalı regresyonlarda, denklem 2'de ifade edilen model her geçişte bir gözlem artırılan örnek verinin, alt kümelerini kullanarak tekrar tekrar tahmin edilir (Philips, Shi ve Yu, 2015b: 1080-1085).

\section{Bulgular}

Türkiye geneli ile Ankara, İstanbul ve İzmir şehirleri için reel hedonik konut fiyat endekslerine ait tanımlayıcı istatistikler Tablo 2'de görülebilir. 
Tablo 2. Tanımlayıcı İstatistikler

\begin{tabular}{|l|c|c|c|c|c|}
\hline Değişkenler & Ortalama & Maksimum & Minimum & Standart Hata & Reel Fiyatlardaki Artış \\
\hline Türkiye & 153,1969 & 227,6500 & 97,05000 & 42,28405 & $\% 142$ \\
\hline Ankara & 145,6335 & 263,5500 & 95,83000 & 34,90518 & $\% 184$ \\
\hline İstanbul & 178,3791 & 273,6300 & 96,63000 & 63,26710 & $\% 112$ \\
\hline İzmir & 161,0990 & 266,9700 & 98,09000 & 52,27526 & $\% 160$ \\
\hline
\end{tabular}

Tablo 2'de tanımlayıcı istatistikler ile birlikte konut fiyatlarındaki reel artış da verilmiştir. Reel fiyatlardaki artış, konut fiyat endekslerinin hesaplanmaya başladığı Ocak 2010 -Aralık 2018 tarihleri arasında reel konut fiyat endekslerindeki yüzdelik değişimi ifade etmektedir. Bu bağlamda en yüksek fiyat artışının Ankara'da, en yüksek oynaklığın ise İstanbul'da yaşandığı görülmektedir. Konut fiyatlarında en düşük artışın İstanbul'da, en düşük oynaklığın ise Ankara'da gerçekleştiği görülmektedir. Konut fiyat endekslerinde balon oluşup oluşmadığını tespit etmek amacıyla gerçekleştirilen SADF ve GSADF testleri Tablo 3'te incelenebilir.

Tablo 1. SADF ve GSADF Test Sonuçları

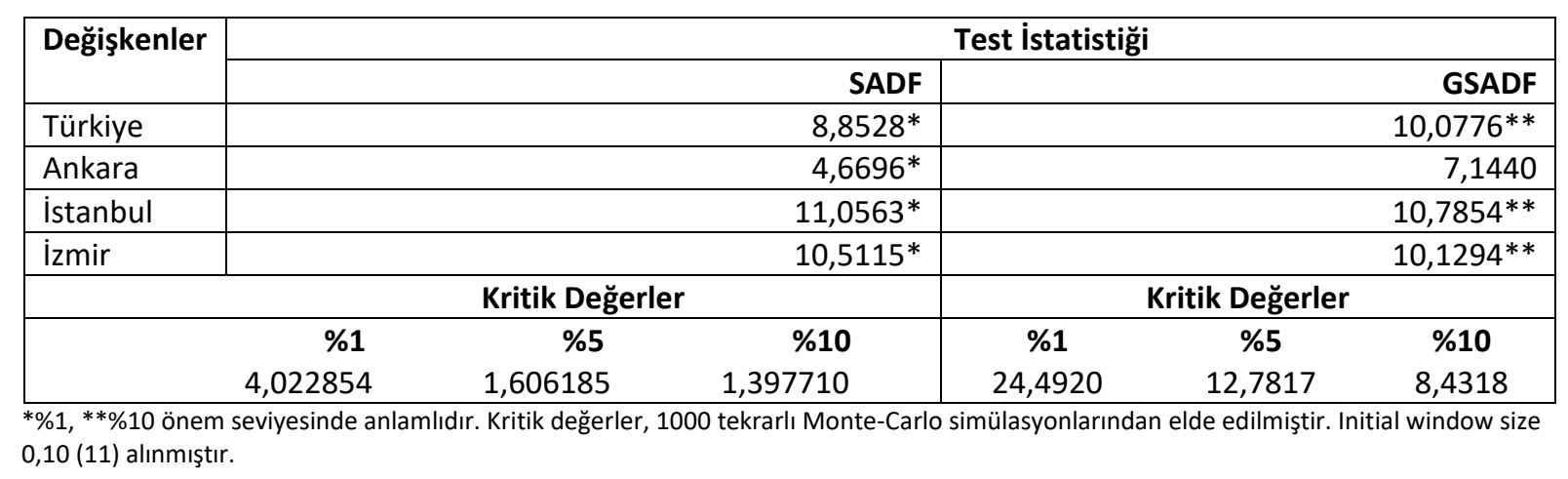

SADF test sonuçlarına göre Türkiye geneli ile Ankara, İstanbul ve İzmir şehirleri için konut fiyatlarında balonların var olduğu tespit edilmiştir. GSADF test sonuçlarına göre ise Ankara'da konut fiyatlarında balonun var olduğuna yönelik istatistiksel olarak anlamlı bir sonuç elde edilememiştir. Tablo 2' de yer alan incelenen dönem aralığında konut fiyat endeksinde en yüksek fiyat artışının Ankara olmasına rağmen ilgili endekste balonun varlığının tespit edilememesi her ne kadar çelişkili gözükse de Ankara'da konut fiyatlarının diğer iki büyük ile göre daha düşük olabileceği ve fiyat artışının bundan kaynaklanması nedeniyle böyle bir sonucun ortaya çıkmış olabileceği değerlendirilmektedir. Ayrıca fiyat artışlarının spekülatif olması balon olarak nitelendirilirken normal fiyat artışları balon olarak nitelendirilmemektedir. Ankara özelinde de fiyat artışlarının spekülatif kaynaklı olmaması bu tür bir durumun ortaya çıkma nedeni olarak değerlendirilebilir. Ancak GSADF test sonuçlarına göre Türkiye geneli ile İstanbul, İzmir için konut fiyatlarında balonların var olduğu tespit edilmiştir. Buna göre Ankara şehrine ilişkin SADF ve GSADF test sonuçları farklıık göstermektedir. Phillips vd. (2015a) çalışmasında SADF testinin birden çok balon olması durumunda yetersiz kalabileceği bu durumda GSADF testlerinin daha başarılı olabileceği ifade edilmiştir. illgili sonuçlar veri aralığının ve kullanılan fiyat endeksinin farklı olduğu Zeren ve Ergüzel (2015), Coşkun ve Jadevicius (2017), Coşkun vd. (2017), Afşar ve Doğan (2018) çalışmalarıyla farklılık arz etmektedir. Bu çalışmada ilgili diğer çalışmalardan farklı olarak daha uzun bir zaman diliminin kullanılmış olması hem de konut fiyat endeksi olarak reel hedonik konut fiyat endeksinin kullanılmış olması sonuçların farklı çıkmasının nedeni olarak görülebilir. Çalışmanın sonuçları, aynı yöntemin kullanıldığı Evrim Mandacı ve Çağıı'nın (2018) çalışmasıyla ve farklı bir yöntemin kullanıldığı Çağı (2018) çalışmasıyla benzerlik göstermektedir. Test sonuçlarına ait grafikler ek 1'de verilmiştir. 


\section{Sonuç}

Bir varlığın gerçek değerinde genellikle spekülatif hareketler sonucu meydana gelen sapmalar, olarak ifade edilen fiyat balonu özellikle piyasaları olumsuz etkilemektedir. Özellikle finansal krizlerin ortaya çıkmasında önemli rol alan fiyat balonlarının tespit edilmesi ekonomik açıdan da önem arz etmektedir. Bu çalışmada da Türkiye geneli ile Ankara, İstanbul ve İzmir şehirleri için konut fiyatlarında balonların oluşup oluşmadığını test etmek amaçlanmıştır. Bu doğrultuda Ocak 2010 ile Aralık 2018 tarihleri arasında aylık reel hedonik fiyat endeksi kullanılarak Phillips vd.'nin (2011) çalışmasında geliştirilen SADF testi ile Phillips vd.'nin (2015a) çalışmasında geliştirilen GSADF testi ile konu incelenmeye çalışılmıştır. Analiz sonucunda, her iki teste göre Türkiye geneli ile İstanbul ve İzmir şehirleri için konut fiyatlarında balonların oluştuğu tespit edilmiştir. Ankara özelinde ise SADF testine göre fiyat balonun var olduğu tespit edilmiş; GSADF testine göre ise fiyat balonunun varlığı istatistiksel olarak anlamlı bulunmamıştır.

Çalışma dönemi boyunca reel konut fiyatlarında Türkiye genelinde \%142, Ankara'da \%184, İstanbul'da \%112 ve İzmir'de \%160 artışın gerçekleştiği düşünüldüğünde fiyat balonu oluşmasına yönelik potansiyel altyapının varlığından söz edilebilir. Ayrıca IMF'nin Şubat 2017'deki Küresel Konut İzleme Raporu'nda, Türkiye'de konut fiyatlarının belirgin bir şekilde arttığı ifade edilmiştir (IMF, 2017: 8). Bu sonuçlara göre konut fiyatlarındaki balonların varlığının, ilerleyen dönemlerde ekonomi üzerinde olumsuz etkisi olabileceği söylenebilir. Özellikle son yıllarda ekonomik büyümenin dinamiklerinden biri olan inşaat sektörü için gerekli tedbirler alınmadığı takdirde, fiyat balonları nedeniyle yaşanabilecek ani fiyat düşüşlerinin de ülke ekonomisini olumsuz etkileyeceği düşünülmektedir. Bu bağlamda Coşkun vd. (2017) ve Çağlı'nın (2018) çalışmalarında da belirtildiği gibi inşaat sektörüne yönelik yapısal kredi ve teşvik düzenlemelerinin gerçekleştirilip finansman maliyetlerinin iyileştirilmesi, konut piyasasının arz yönüne ilişkin öneriler olarak kabul edilebilir. Diğer yandan özellikle nüfus yoğunluğunun bulunduğu illerde TOKí öncülüğünde uygun vadeli ve hesaplı konut yapımının artırılarak devam etmesi, konut arzını artırarak fiyatlardaki artışın önüne geçecek ve talep yönünden de canlılığın devam etmesini teşvik edebilecektir.

Bundan sonra yapılacak benzer çalışmalarda konutların metrekare maliyetlerinde ve konut kiralarında da bir fiyat balonunun oluşup oluşmadığının tespit edilmesi, sonuçların genelleştirilmesi anlamında literatüre katkı sağlayabilir. Ayrıca konut fiyat balonlarının oluştuğu dönemlerde ekonomideki diğer göstergeler ile konut fiyatları arasında nasıl bir ilişki olduğu da diğer çalışmaların konusunu oluşturabilir.

\section{Kaynaklar}

Ahamed, L. (2009). Lords of finance: The bankers who broke the world. New York: Penguin Press.

Afşar, A., \& Doğan, E. (2018). Analyzing asset of bubbles in the housing market with right-tailed unit root tests: The case of Turkey. Journal of Business Economics and Finance, 7(2), 139-147.

Atasever, G. (2016). Varlık fiyatları köpüğü: Muğla konut piyasası üzerine bir değerlendirme. Akdeniz Üniversitesi Iktisadi ve Idari Bilimler Fakültesi Dergisi, 16(34), 1-17.

Brunnermeier, M. K. (2008). Bubbles. The New Palgrave Dictionary of Economics, 1-8, 578-583.

Campbell, J. Y., \& Shiller, R. J. (1987). Cointegration and tests of present value models. Journal of Political Economy, 95(5), 1062-1088.

Case, K. E., \& Shiller, R. J. (2003). Is there a bubble in the housing market? Brookings Papers on Economic Activity, 2003(2), 299-362.

Caspi, I. (2013). Rtadf: Testing for bubbles with EViews. MPRA Paper No. 58791. https://mpra.ub.unimuenchen.de/58791/1/MPRA_paper_58791.pdf (Erişim Tarihi: 10.07.2019).

Chen, X., \& Funke, M. (2013). Renewed momentum in the German housing market: Boom or bubble? Cesifo Working Paper No. 4287 Ludwig Maximilian University.

Glaeser, E., Huang, W., Ma, Y., \& Shleifer, A. (2017). A real estate boom with Chinese characteristics. Journal of Economic Perspectives, 31(1), 93-116.

Coşkun, Y., \& Jadevicius, A. (2017). Is there a housing bubble in Turkey? Real Estate Management and Valuation, 25(1), 48-73. 
Coşkun, Y., Seven, U., Ertugrul, H. M., \& Alp, A. (2017). Housing price dynamics and bubble risk: The case of Turkey. Housing Studies, 1-37.

Çağlı, E. C. (2018). Explosive behavior in the real estate market of Turkey. Borsa Istanbul Review, In Press, 1-6.

Diba, B. T., \& Grossman, H. I. (1988). Explosive rational bubbles in stock prices? The American Economic Review, 78(3), 520-530.

El Montasser, G., Gupta, R., Martins, A. L., \& Wanke, P. (2015). Are there multiple bubbles in the ethanol-gasoline price ratio of Brazil? Renewable and Sustainable Energy Reviews, 52, 19-23.

Engsted, T., Hviid, S. J., \& Pedersen, T. Q. (2016). Explosive bubbles in house prices? Evidence from the OECD countries. Journal of International Financial Markets, Institutions and Money, 40, 14-25.

Escobari, D., \& Jafarinejad, M. (2016). Date stamping bubbles in real estate investment trusts. The Quarterly Review of Economics and Finance, 60, 224-230.

Evrim Mandacı, P., \& Çağlı, E. Ç. (2018). Türkiye konut piyasasında balon var mı? İstatistiki bölge birimleri üzerine bir analiz. Finans Politik \& Ekonomik Yorumlar, 55(646), 85-113.

Fabozzi, F. J., Kynigakis, I., Panopoulou, E., \& Tunaru, R. S. (2019). Detecting bubbles in the US and UK real estate markets. The Journal of Real Estate Finance and Economics, 58(3), 1-45.

Fabozzi, F. J., \& Xiao, K. (2018). The timeline estimation of bubbles: The case of real estate. Real Estate Economics. 1-35.

Fama, E. F. (1991). Efficient capital markets: II. The Journal of Finance, 46(5), 1575-1617.

Homm, U., \& Breitung, J. (2012). Testing for speculative bubbles in stock markets: A comparison of alternative methods. Journal of Financial Econometrics, 10(1), 198-231.

Hu, Y., \& Oxley, L. (2017). Are there bubbles in exchange rates? Some new evidence from G10 and emerging market economies. Economic Modelling, 64, 419-442.

Hu, Y., \& Oxley, L. (2018). Bubble contagion: Evidence from Japan's asset price bubble of the 1980-90s. Journal of the Japanese and International Economies, 50, 89-95.

Hülagü, T., Kızılkaya, E., Özbekler, A. G., \& Tunar, P. (2016). Türkiye konut fiyat endeksinin kalite değişimi etkisinden arındırılması: Hedonik konut fiyat endeksi. TCMB Ekonomi Notları, 2016(2), 1-15.

IMF, (2017). Global housing watch report. International Money Fund, https://www.imf.org/external/research/housing/report/pdf/Q1_2017.pdf (Erişim Tarihi: 03.02.2019).

Kim, K. H., \& Lee, H. S. (2000, July). Real estate price bubble and price forecasts in Korea. In Asia Real Estate Society Fifth Annual Conference, Beijing (pp. 26-30).

Lind, H. (2009). Price bubbles in housing markets: Concept, theory and indicators. International Journal of Housing Markets and Analysis, 2(1), 78-90.

Phillips, P. C., Wu, Y., \& Yu, J. (2011). Explosive behavior in the 1990s Nasdaq: When did exuberance escalate asset values? International economic review, 52(1), 201-226.

Phillips, P. C., Shi, S., \& Yu, J. (2015a). Testing for multiple bubbles: Historical episodes of exuberance and collapse in the S\&P 500. International Economic Review, 56(4), 1043-1078.

Philips, P.C.B., Shi, S., \& Yu, J. (2015b). Testing for multiple bubbles: Limit theory of dating algorithms. International Economic Review, 52, 1079-1134.

Santoni, G. J. (1987). The great bull markets 1924-29 and 1982-87: Speculative bubbles or economic fundamentals? Federal Reserve Bank of St. Louis Review, 69(9), 16-29.

Shi, S., Valadkhani, A., Smyth, R., \& Vahid, F. (2016). Dating the timeline of house price bubbles in Australian capital cities. Economic Record, 92(299), 590-605.

Shiller, R. J. (2003). From efficient markets theory to behavioral finance. Journal of Economic Perspectives, 17(1), 83104.

TCMB (Türkiye Cumhuriyet Merkez Bankası), Konut Fiyat https://evds2.tcmb.gov.tr/index.php?/evds/dashboard/310 (Erişim Tarihi: 03.02.2019).

Zeren, F., \& Ergüzel, O. S. (2015). Testing for bubbles in the housing market: Further evidence from Turkey. Financial Studies, 19(1), 40-52. 


\section{Ekler}

\section{Ek 1. GSADF Test Sonuçlarına Ait Grafikler}

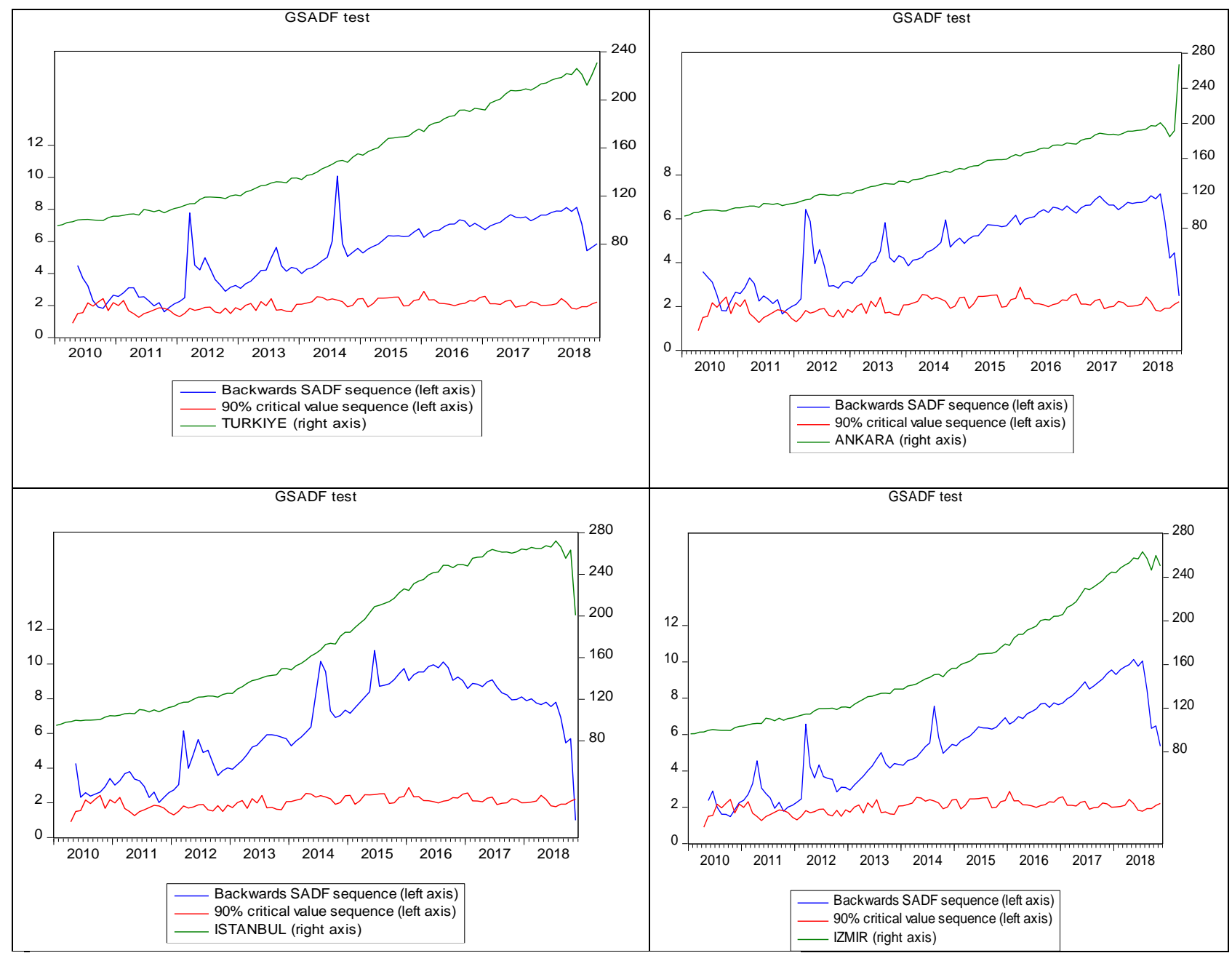

* Kritik değerler tablosu \%10'uda ihtiva ettiğinden beta değeri 0,90 alınmıştır 
This Page Intentionally Left Blank 